\title{
Factors Associated with Utilization of Insecticide Treated Nets Among Residents of Kamwenge Town Council-Kamwenge District-Uganda
}

\author{
Ikiriza Antony ${ }^{1,}$ ", Maureen Andinda ${ }^{1}$, Kamukama Robert ${ }^{1}$, Mugisa Tony ${ }^{1}$, Rubaihayo John ${ }^{2}$, \\ Arseni R. Semana ${ }^{3}$ \\ ${ }^{1}$ Department of Public Health, Mountains of the Moon University, Fort Portal, Uganda \\ ${ }^{2}$ School of Health Sciences, Mountains of the Moon University, Fort Portal, Uganda \\ ${ }^{3}$ School of Agriculture and Environmental Science, Mountains of the Moon University, Fort Portal, Uganda
}

Email address:

iantony2011@gmail.com (I. Antony)

${ }^{*}$ Corresponding author

\section{To cite this article:}

Ikiriza Antony, Maureen Andinda, Kamukama Robert, Mugisa Tony, Rubaihayo John, Arseni R. Semana. Factors Associated with Utilization of Insecticide Treated Nets Among Residents of Kamwenge Town Council-Kamwenge District-Uganda. International Journal of Infectious Diseases and Therapy. Vol. 4, No. 1, 2019, pp. 1-6. doi: 10.11648/j.ijidt.20190401.11

Received: February 20, 2019; Accepted: March 26, 2019; Published: April 18, 2019

\begin{abstract}
Background: Malaria continues to be a leading cause of morbidity and mortality in sub-Saharan Africa. In Uganda, malaria remains the leading cause of morbidity, accounting for 30 to 50 percent of outpatient visits, 15 to 20 percent of admissions, and 9 to 14 percent of inpatient deaths. The first national-wide Insecticide Treated Nets (ITNs) coverage campaign was launched in 2010 targeted at households with pregnant women and children below 5yrs of age. Objective: To determine the factors associated with utilization of Insecticide Treated Nets (ITNs) among residents of Kamwenge Town Council, Kamwenge DistrictWestern Uganda. Methodology: The study design was cross-sectional in which data were collected using an interviewer administered structured questionnaire and analyzed using Stata version 13. Results: A total of 285 respondents were interviewed of which $39.7 \%$ were male. Ownership of ITNs was $60 \%$ whereas utilization in the night prior to the study was $54.4 \%$. The factors associated with the ownership of the ITNs included: marital status: married respondents $(p=0.05)$, level of education $(p=0.001)$, knowledge of malaria cause $(p=0.033)$, presence of children under 5 years $(p=0.025)$. The factors associated with the utilization of ITNs included: marital status of the respondents: married respondents $(p=0.018)$, education level $(p=0.009)$, presence of children under five years $(p=0.048)$, knowledge of cause of malaria $(p=0.019)$, having faced challenges in using ITNs $(p=0.001)$, and malaria episode in the last one month $(p=0.011)$. Conclusion: The study concludes that the ownership and utilization of ITNs were low since they were all below the national target of universal coverage. The factors statistically associated with the ownership of the ITNs included: marital status, level of education, knowledge of malaria cause and the number of children under 5 years in a household. The factors statistically associated with the utilization of ITNs were marital status, education level of the respondents, and presence of children under five years of age in the household, having knowledge about malaria, having faced challenges in using ITNs in the past and malaria episode in the last one month.
\end{abstract}

Keywords: Residents, Insecticide Treated Nets (ITNS), Utilization

\section{Background}

Malaria is the leading cause of morbidity and mortality in the tropical religion accounting for 3.2 billion deaths with its peak of 1.2 million in 2013 and Malaria mortality has been steadily decreasing since 1990 but $90 \%$ of the deaths occurred in Africa with Uganda having the third highest number of malaria cases after Democratic Republic of Congo and Nigeria $[1,2,4]$.

The World Health Organization's Global Malaria Programme recommends use of Insecticide-Treated Nets (ITNs) as one of the three major means of malaria vector control to reduce malaria transmission but in 2013 , only $49 \%$ of the people at risk 
in Sub Saharan Africa had access to ITNs yet ITNs efficacy against malaria episodes of approximately $50 \%$ [2-5].

Uganda adopted a policy of universal LLIN coverage of one net per two persons to protect all people from malaria and conducted a community mass campaigns and through public health facilities that target pregnant women and children under 5 years on a routine basis and several community mass distribution of nets since 2010 [6].

However, the utilization of ITNs in Kamwenge Town Council is still not known and the study aimed at determining the factors that influence utilization of ITNs among residents of Kamwenge Town Council.

\section{Methodology}

\subsection{Study Design and Setting}

This was a household based survey that was conducted in Kamwenge Town Council that the main town of the district and a centre for most of the activities like Administrative services, business and other social amnesties located in Western Uganda a distance of $400 \mathrm{~km}$ from the capital city Kampala by road.

\subsection{Sample Size Estimation, Sampling Procedure and Data Collection}

The sample 299 was determined using a standard formula by Kish Leslie assuming a standard error of 5\% and $77.1 \%$ of households with at least one insecticide- treated net in Tooro region and 10\% non-response was included [7-8]. Kamwenge Town council was selected purposively because it in the center of the district and has a mix of people from different backgrounds. A household list for each ward was obtained with the aid of the ward agents and they were used to randomly assign households to different research assistants during the data collection process. Household heads were interviewed and in case they were absent, the oldest household member 18 years and above was selected for the interview using a structured questionnaire that contained both close and open ended questions.

\subsection{Ethical Considerations}

Ethical approval was obtained from the Mountains of the Moon University, Directorate of Postgraduate Studies\& Research seeking permission to conduct the study which was presented to the officials of the Kamwenge Town and written informed consent was obtained from the study participants.

\subsection{Data Analysis}

Data was analysed using STATA version 13 for data analysis, Chi square test was used to identify the factors that influence the utilization of ITNs. To identify the factors that are associated with utilization of ITNs, logistic regression analysis was used in which bivariate logistic regression was first used to identify the factors that could be associated with utilization of ITNs at a p-value $<0.05$ and the factors that were turned out to be associated with utilization of ITNs in the bivariate analysis were included into a multivariate logistic regression model to cater for the effect of confounders and effect modifiers and identify the independent predictors of utilization of ITNs.

\section{Results}

\subsection{Demographic Characteristics}

A total of 285 respondents were surveyed in July 2017. Majority of the respondents were aged 30-49 years 151 (53\%) with a mean age of 39.7 years, females $172(60.4 \%)$ and married $221(77.8 \%)$ more demographic characteristics shown in (table 1).

Table 1. Demographic Characteristics of the respondents $(n=285)$.

\begin{tabular}{|c|c|c|}
\hline Variable & Category & Frequency, n (\%) \\
\hline \multirow{4}{*}{ Age in years } & $10-29$ & $72(25.3)$ \\
\hline & $30-49$ & $151(53)$ \\
\hline & $50-69$ & $56(19.7)$ \\
\hline & 70 and above & $6(2)$ \\
\hline \multirow{2}{*}{$\operatorname{Sex}$} & Female & $172(60.4)$ \\
\hline & Male & $113(39.6)$ \\
\hline \multirow{4}{*}{ Marital status } & Single & $19(6.7)$ \\
\hline & Married & $222(77.8)$ \\
\hline & Divorced & $15(5.3)$ \\
\hline & Widow & $29(10.2)$ \\
\hline \multirow{4}{*}{ Level of Education } & No Education & $136(47.7)$ \\
\hline & Primary & $96(33.7)$ \\
\hline & Secondary & $37(13)$ \\
\hline & Tertiary & $16(5.6)$ \\
\hline \multirow{4}{*}{ Occupation } & Business & $45(15.8)$ \\
\hline & Civil Servant & $16(5.6)$ \\
\hline & Farmer & $210(73.7)$ \\
\hline & Housewife & $14(4.9)$ \\
\hline \multirow{4}{*}{ Religion } & Bornagain & $28(9.8)$ \\
\hline & Catholic & $150(52.6)$ \\
\hline & Islam & $12(4.2)$ \\
\hline & Protestant & $95(33.3)$ \\
\hline \multirow{5}{*}{ No children under 5 years } & 0 & $126(44.2)$ \\
\hline & 1 & $77(27.0)$ \\
\hline & 2 & $59(20.7)$ \\
\hline & 3 & $17(6.0)$ \\
\hline & 4 & $6(2.1)$ \\
\hline \multirow{4}{*}{$\begin{array}{l}\text { Number of people in the } \\
\text { household }\end{array}$} & $1-5$ & $186(62.3)$ \\
\hline & $6-10$ & $90(31.6)$ \\
\hline & $11-16$ & $8(2.8)$ \\
\hline & $17-22$ & $1(0.35)$ \\
\hline \multirow{2}{*}{ Ownership of ITNs } & No & $114(40)$ \\
\hline & Yes & $171(60)$ \\
\hline \multirow{2}{*}{ Utilization of ITNs by adults } & No & $130(45.6)$ \\
\hline & Yes & $155(54.4)$ \\
\hline \multirow{2}{*}{$\begin{array}{l}\text { Utilization of ITNs by } \\
\text { children }<5 \text { years }\end{array}$} & No & $54(34)$ \\
\hline & Yes & $105(66)$ \\
\hline \multirow{6}{*}{$\begin{array}{l}\text { Number ITNs observed per } \\
\text { household }\end{array}$} & 1 & $74(43.3)$ \\
\hline & 2 & $66(38.6)$ \\
\hline & 3 & $22(12.9)$ \\
\hline & 4 & $7(4.1)$ \\
\hline & 6 & $1(0.6)$ \\
\hline & 7 & $1(0.6)$ \\
\hline \multirow{2}{*}{ Type of the ITN owned } & Polyester nets & $42(24.6)$ \\
\hline & Nylon nets & $129(75.4)$ \\
\hline
\end{tabular}

Source: Field data, 2017 


\subsection{ITN Ownership by Demographic Characteristics}

The study found out a significant difference in the ownership of ITNs a cross the different marital statuses $\left(X^{2}\right.$ $=12.50, p=0.006$ ), levels of education whereby those with secondary and above level of education were more likely to own the nets $\left(X^{2}=33.55, p=0.001\right)$ as well as occupation of the respondents, number of children $<5$ years in the household and number of people in household shown in table 2 below.

Table 2. ITN Ownership by demographic Characteristics.

\begin{tabular}{|c|c|c|c|c|}
\hline \multirow{2}{*}{ Variable } & \multicolumn{2}{|c|}{ ITN ownership } & \multirow{2}{*}{$X^{2}$} & \multirow{2}{*}{ P-value } \\
\hline & No n (\%) & Yes n (\%) & & \\
\hline \multicolumn{5}{|l|}{ Age } \\
\hline $10-29$ & $30(41.7)$ & $42(58.3)$ & \multirow{5}{*}{3.17} & \multirow{5}{*}{0.366} \\
\hline $30-49$ & $55(36.4)$ & $96(63.6)$ & & \\
\hline $50-69$ & $25(44.6)$ & $31(55.4)$ & & \\
\hline 70 and above & $4(66.7)$ & $2(33.3)$ & & \\
\hline \multicolumn{3}{|l|}{ Sex } & & \\
\hline Female & 67 (38.9) & $105(61.1)$ & \multirow{3}{*}{0.20} & \multirow{3}{*}{0.656} \\
\hline Male & $47(41.6)$ & $66(58.4)$ & & \\
\hline \multicolumn{3}{|l|}{ Marital status } & & \\
\hline Single & $10(52.6)$ & $9(47.4)$ & \multirow{4}{*}{12.50} & \multirow{4}{*}{$0.006^{*}$} \\
\hline Married & $82(36.9)$ & $140(63.1)$ & & \\
\hline Divorced & $12(80.0)$ & $3(20.0)$ & & \\
\hline Widow & $10(34.5)$ & $19(65.5)$ & & \\
\hline \multicolumn{5}{|l|}{ Education level } \\
\hline No Education & $68(50.8)$ & $66(49.2)$ & \multirow{4}{*}{33.55} & \multirow{4}{*}{$0.001 *$} \\
\hline Primary & $43(43.9)$ & $55(56.1)$ & & \\
\hline Secondary & $1(2.7)$ & $36(97.3)$ & & \\
\hline Tertiary & $2(12.5)$ & $14(87.5)$ & & \\
\hline \multicolumn{5}{|l|}{ Occupation } \\
\hline Business & $14(31.1)$ & $31(68.9)$ & \multirow{5}{*}{17.51} & \multirow{5}{*}{$0.001 *$} \\
\hline Civil Servant & $0(0.0)$ & $16(100.0)$ & & \\
\hline Farmer & $97(46.2)$ & $113(53.8)$ & & \\
\hline Housewife & $3(21.4)$ & $11(78.6)$ & & \\
\hline \multicolumn{3}{|l|}{ Religion } & & \\
\hline Bornagain & $15(53.6)$ & $13(46.4)$ & \multirow{4}{*}{4.10} & \multirow{4}{*}{0.252} \\
\hline Catholic & $62(41.3)$ & $88(58.7)$ & & \\
\hline Islam & $3(25.0)$ & $9(75.0)$ & & \\
\hline Protestant & $34(35.8)$ & $61(64.2)$ & & \\
\hline \multicolumn{5}{|c|}{ Number of children $<5$ years } \\
\hline 0 & $62(49.2)$ & $64(50.8)$ & \multirow{5}{*}{10.90} & \multirow{5}{*}{$0.028^{*}$} \\
\hline 1 & $25(32.5)$ & $52(67.5)$ & & \\
\hline 2 & $21(35.6)$ & $38(64.4)$ & & \\
\hline 3 & $6(35.3)$ & $11(64.7)$ & & \\
\hline 4 & $0(0.0)$ & $6(100.0)$ & & \\
\hline \multicolumn{5}{|c|}{ Number of people in household } \\
\hline $1-5$ & $71(38.2)$ & $115(61.8)$ & & \\
\hline $6-10$ & $43(47.8)$ & $47(52.2)$ & 853 & $0036 *$ \\
\hline $11-16$ & $0(0.0)$ & $8(100.0)$ & 8.53 & $0.030^{\circ}$ \\
\hline $17-22$ & $0(0.0)$ & $1(100.0)$ & & \\
\hline
\end{tabular}

Source: Field data, 2017

* Significantly associated at $\mathrm{p}<0.05$

\subsection{ITN Utilization by Demographic Characteristics}

There was a significant difference in ITN utilization across the different marital statuses of the respondents, with married respondents utilizing nets more than any other $\left(X^{2}=11.49\right.$, $p=0.009$ ), education level where by those educated to secondary level and beyond utilizing the nets than those who are not $\left(X^{2}=35.25, p=0.001\right)$ and other characteristics as shown in table 3 below.
Table 3. ITN utilization by demographic characteristics.

\begin{tabular}{|c|c|c|c|c|}
\hline \multirow{2}{*}{ Variable } & \multicolumn{2}{|c|}{ ITN utilization } & \multirow{2}{*}{$X^{2}$} & \multirow{2}{*}{ P-value } \\
\hline & No n $(\%)$ & Yes n (\%) & & \\
\hline \multicolumn{5}{|l|}{ Age } \\
\hline $10-29$ & $32(44.4)$ & $40(55.6)$ & \multirow{5}{*}{1.13} & \multirow{5}{*}{0.769} \\
\hline $30-49$ & $69(45.7)$ & $82(54.3)$ & & \\
\hline $50-69$ & $25(44.6)$ & $31(55.4)$ & & \\
\hline 70 and above & $4(66.7)$ & $2(33.3)$ & & \\
\hline \multicolumn{3}{|l|}{$\operatorname{Sex}$} & & \\
\hline Female & 79 (45.9) & $93(54.1)$ & \multirow{2}{*}{0.018} & \multirow{2}{*}{0.895} \\
\hline Male & $51(45.1)$ & $62(54.9)$ & & \\
\hline \multicolumn{5}{|l|}{ Marital status } \\
\hline Single & $10(52.6)$ & $9(47.4)$ & \multirow{4}{*}{11.49} & \multirow{4}{*}{$0.009 *$} \\
\hline Married & $95(42.8)$ & $127(57.2)$ & & \\
\hline Divorced & $13(86.7)$ & $2(13.3)$ & & \\
\hline Widow & $12(41.4)$ & $17(58.6)$ & & \\
\hline \multicolumn{5}{|c|}{ Education level } \\
\hline No Education & $79(59.0)$ & $55(41.0)$ & \multirow{4}{*}{35.25} & \multirow{4}{*}{$0.001 *$} \\
\hline Primary & $45(45.9)$ & $53(54.1)$ & & \\
\hline Secondary & $3(8.1)$ & $34(91.9)$ & & \\
\hline Tertiary & $3(18.8)$ & $13(81.2)$ & & \\
\hline \multicolumn{3}{|l|}{ Occupation } & \multirow{6}{*}{17.78} & \multirow{6}{*}{$0.001 *$} \\
\hline Business & $17(37.8)$ & $28(62.2)$ & & \\
\hline Civil Servant & $1(6.2)$ & $15(93.8)$ & & \\
\hline Farmer & 109 (51.9) & $101(48.1)$ & & \\
\hline Housewife & $3(21.4)$ & $11(78.6)$ & & \\
\hline \multicolumn{3}{|l|}{ Religion } & & \\
\hline Bornagain & $17(60.7)$ & $11(39.3)$ & \multirow{4}{*}{5.60} & \multirow{4}{*}{0.133} \\
\hline Catholic & $71(47.3)$ & $79(52.7)$ & & \\
\hline Islam & $3(25.0)$ & $9(75.0)$ & & \\
\hline Protestant & $39(41.0)$ & $56(59.0)$ & & \\
\hline \multicolumn{3}{|c|}{ Number of children $<5$ years } & \multirow{6}{*}{10.34} & \multirow{6}{*}{$0.035^{*}$} \\
\hline 0 & $68(54.0)$ & $58(46.0)$ & & \\
\hline 1 & $30(39.0)$ & $47(61.0)$ & & \\
\hline 2 & $25(42.4)$ & $34(57.6)$ & & \\
\hline 3 & $7(41.2)$ & $10(58.8)$ & & \\
\hline 4 & $0(0.0)$ & $6(100.0)$ & & \\
\hline \multicolumn{5}{|c|}{ Number of people in household } \\
\hline $1-5$ & $82(44.1)$ & $104(55.9)$ & & \\
\hline $6-10$ & $47(52.2)$ & $43(47.8)$ & 613 & 0.105 \\
\hline $11-16$ & $1(12.5)$ & $7(87.5)$ & 0.13 & 0.105 \\
\hline $17-22$ & $0(0.0)$ & $1(100.0)$ & & \\
\hline
\end{tabular}

Source: Field data, 2017

* Significantly associated at $\mathrm{p}<0.05$

\subsection{Factors Associated with Utilization of ITNs Among Residents of Kamwenge Town Council}

The factors that were identified to have a statistically significant relationship with the utilization of ITNs in the bivariate analysis at a $p$-value $<0.05$ included: marital status, level of education, occupation, religion, knowledge of malaria cause, number of children under 5 years in a household, malaria experience in the last one month and challenge in using ITNs. These were included in a multivariate logistic regression model to identify the predictors of utilization of ITNs as shown in table 4 below. 
Ikiriza Antony et al:: Factors Associated with Utilization of Insecticide Treated Nets Among Residents of

Kamwenge Town Council-Kamwenge District-Uganda

Table 4. Factors associated with utilization of ITNs among residents of Kamwenge Town council.

\begin{tabular}{|c|c|c|c|c|}
\hline \multirow{2}{*}{ Variable } & \multicolumn{2}{|l|}{ Bivariate analysis } & \multicolumn{2}{|l|}{ Multivariate analysis } \\
\hline & cOR $(95 \% \mathrm{CI})$ & P-value & aOR $(95 \% C I)$ & P-value \\
\hline \multicolumn{5}{|l|}{ Age } \\
\hline $18-29$ & 1 & & & \\
\hline $30-49$ & $0.95(0.54-1.67)$ & 0.861 & & \\
\hline $50-69$ & $0.99(0.49-2.00)$ & 0.982 & & \\
\hline 70 and Above & $0.4(0.07-2.32)$ & 0.308 & & \\
\hline \multicolumn{5}{|l|}{ Sex } \\
\hline Female & 1 & & & \\
\hline Male & $1.03(0.64-1.66)$ & 0.895 & & \\
\hline \multicolumn{5}{|l|}{ Marital status } \\
\hline Divorced & 1 & & 1 & \\
\hline Married & $8.70(1.92-39.42)$ & $0.005^{*}$ & $8.4(1.44-49.40)$ & $0.018^{*}$ \\
\hline Single & $5.85(1.03-33.33)$ & $0.047 *$ & $4(0.40-31.26)$ & 0.257 \\
\hline Widow & $9.21(1.75-48.53)$ & $0.009^{*}$ & $12(1.70-84.05)$ & $0.013 *$ \\
\hline \multicolumn{5}{|l|}{ Education level } \\
\hline No education & 1 & & 1 & \\
\hline Primary & $1.69(1.00-2.86)$ & $0.050^{*}$ & $1.1(0.58-2.23)$ & 0.713 \\
\hline Secondary & $16.28(4.76-55.67)$ & $0.001 *$ & $6.3(1.57-25.65)$ & $0.009 *$ \\
\hline Tertiary & $6.22(1.69-22.88)$ & $0.006^{*}$ & $2.0(0.30-13.64)$ & 0.486 \\
\hline \multicolumn{5}{|l|}{ Occupation } \\
\hline Business & 1 & & 1 & \\
\hline Civil servant & $9.11(1.10-75.27)$ & $0.040 *$ & $3.7(0.27-50.20)$ & 0.328 \\
\hline Farmer & $0.56(0.29-0.09)$ & 0.088 & $0.5(0.16-1.24)$ & 0.121 \\
\hline Housewife & $2.23(0.54-9.13)$ & 0.267 & $2.5(0.43-14.71)$ & 0.308 \\
\hline \multicolumn{5}{|l|}{ Religion } \\
\hline Bornagain & 1 & & 1 & \\
\hline Catholic & $1.72(0.75-3.92)$ & 0.197 & $0.9(0.29-3.10)$ & 0.926 \\
\hline Islam & $4.64(1.02-21.00)$ & $0.047 *$ & $1.3(0.18-9.23)$ & 0.791 \\
\hline Protestant & $2.22(1.00-5.25)$ & 0.070 & $1.1(0.32-3.62)$ & 0.907 \\
\hline \multicolumn{5}{|c|}{ Number of children $<5$ years } \\
\hline 0 & 1 & & 1 & \\
\hline 1 & $1.84(1.03-3.27)$ & $0.039^{*}$ & $2.1(1.01-4.47)$ & $0.048 *$ \\
\hline 2 & $1.59(0.85-2.98)$ & 0.143 & $3.0(1.34-6.64)$ & $0.007 *$ \\
\hline 3 & $1.67(0.60-4.68)$ & 0.325 & $3.3(0.90-12.14)$ & 0.071 \\
\hline \multicolumn{5}{|c|}{ Knowledge of malaria cause } \\
\hline Knowledgeable & 1 & & 1 & \\
\hline Not Knowledgeable & $1.53(0.33-0.85)$ & $0.009^{*}$ & $0.5(0.26-0.90)$ & $0.019^{*}$ \\
\hline \multicolumn{5}{|c|}{ Knowledge of use of ITNs } \\
\hline Knowledgeable & 1 & & & \\
\hline Not knowledgeable & $0.44(0.15-1.26)$ & 0.125 & & \\
\hline \multicolumn{5}{|l|}{ Quality of the nets } \\
\hline Intact & 1 & & & \\
\hline Torn & $1.29(0.46-3.62)$ & 0.628 & & \\
\hline \multicolumn{5}{|c|}{ Challenge in using ITNs } \\
\hline Had challenge & 1 & & 1 & \\
\hline Had no challenge & $4.27(2.50-7.27)$ & $0.001 *$ & $6.1(3.12-12.03)$ & $0.001 *$ \\
\hline \multicolumn{5}{|c|}{ Malaria experience in the last one month } \\
\hline No & 1 & & 1 & \\
\hline Yes & $0.42(0.25-0.69)$ & $0.001 *$ & $0.4(0.20-0.81)$ & $0.011 *$ \\
\hline
\end{tabular}

Source: Field data, 2017,

* Significantly associated at $\mathrm{p}<0.05$,

cOR-Crude odds ratio,

aOR-Adjusted odds ratio

CI-Confidence interval

\section{Discussions}

More than a half of the respondents $54.4 \%$ had slept under ITNs the night prior to the study. This could be because some people do not have the bed nets and others prefer not to use them. This agrees with Uganda Malaria Indicator Survey [6] findings that reported that $69 \%$ of the de facto household population slept under an ITN the night before the survey.

Of the 159 households that had a child below 5 years, 54 (34\%) reported that no child had slept under an ITN [9] also found out that despite the fact that ownership has been stable, available evidence shows that utilization of ITNs among 
children under five years of age has been low which is a gap between ownership and utilization is large.

Marital was found to statistically association with the utilization of the ITNs whereby married respondents slept under ITNs 8 times more than the divorced $(a O R=8.4,95 C I$ : 1.44-49.40, $p=0.018$ ), widows also slept under ITNs 12 times more than the divorced $(a O R=12,95 \% C I: 1.70-84.05$, $p=0.013$ ) and the single respondents also slept under the ITNs 4 times more than the divorced ones. Given the fact they are in stable relationships, sleeping patterns could also be quite stable hence a high level of using ITNs than the divorced whose relationships are not stable.

The study found a statistically significant association between education level of the respondents and the use of ITNs whereby respondents who had attained secondary level of education slept under ITNs 6 times more than the un educated ones $(a O R=6,95 \% C I: 1.57-25.65, p=0.009)$ and the ones who had attained a tertiary level of education also slept under ITNs 2 times more than the un educated ones. This implies that such respondents are informed about the use of the ITNs and end up using the more than the uneducated who may not know. This finding is in line with findings of the study by Binka and others [9] who found out that demographic characteristics like age, education, size of household and ethnicity also influence use of bed nets.

Households in which there were children under five years of age used ITNs more than those in which there were no children and the association between the numbers of children in the household was statistically associated with the use of ITNs with households with one child using ITNs 2 times more than those in which there are no children and household with two children 3 times more than those without any children. This could be due to the fact that the Government of Uganda promotes use of mosquito nets by pregnant women and children under five years by providing mosquito nets to such women when they were pregnant which increases the ownership as well as use. This could also be due to the fact that the parents want to protect their children from malaria. This is in line with the findings by Biadgilign et al, [10] on determinants of ownership and utilization of insecticide treated nets for malaria control in Eastern Ethiopia that showed that households which had at least one under- five child the odds of owning any net was about $60 \%$ higher than those with no under-five children.

Having knowledge about malaria cause was statistically associated with the utilization of ITNs. The knowledgeable respondents slept under ITNs 0.5 times more than those who were not knowledgeable $(a O R=0.5 ; 95 \% C I$ : 0.26-0.90, $p=0.019$ ). This implies that knowing how to prevent increases possibility for such people to sleep under ITNs and this is in agreement with findings of studies by Berhane, and Worku, 2012 [11] that documented that the key factors which explain the use of ITNs for malaria prevention relate to perceptions, attitude and retention level of ITNs and that use of ITNs was found to be low among people with little knowledge on malaria prevention methods.

Having faced challenges in using ITNs in the past was also statistically associated with the use of ITNs where by the respondents who had no challenges slept under ITNs 6 times more than those that had challenges. This is due to the fact that such challenges like heat and allergies inconvenience the people's sleep and discourage use of the ITNs. This is in line with the findings of the study by [13] that found that the main reasons for not using LLINs were inconveniences due to heat, no LLIN and LLIN is washed or torn, [14] also reported similar findings such as forgetfulness, unavailability of nets, net washed, fatigue, illness, and heat.

Respondents who had suffered from malaria in the last one month slept under ITNs 0.4 times less than the ones who had not suffered from malaria and the relationship between malaria experience and ITNs use was statistically significant $(a O R=0.4,95 \% C I: 0.20-0.81, p=0.011)$. This implies that suffering from malaria does not influence the use of ITNs but Onwejekwe et al, in 2013 reported a different finding that perceived risk of malaria and benefits of the nets by the population also drive demand and that households with a recent attack of malaria were more likely to purchase net than their counterparts and that such communities have a perceived need for utilizing ITNs [13].

\section{Conclusions}

Utilization of ITNs was found to be $54.4 \%$ and almost a half of the respondents surveyed did not sleep under the net a night prior to the study. The factors that were found to be significantly associated with the use of ITNs are marital, education level of the respondents, presence of children under five years of age in the household, having knowledge about malaria, having faced challenges in using ITNs in the past and malaria experience in the last one month. To maximize the benefits of use of mosquito nets, strategies to deal with unwanted or damaged ITNs and other bed nets should be put in place since people are still using torn and old ITNs.

\section{Ethics and Consent to Participate}

Ethical approval was sought from the Directorate of Graduate studies and research Mountains of the Moon University Research and Ethics Committee and all participants consented in writing at the time of interview in their homes.

\section{List of Abbreviations}

$\begin{array}{ll}\text { ITNs } & \text { Insecticide Treated Nets } \\ \text { LLINs } & \text { Long Lasting Insecticide Nets } \\ \text { MOH } & \text { Ministry of Health } \\ \text { NMCP } & \text { National Malaria Control Programme } \\ \text { UMIS } & \text { Uganda Malaria Indicator Survey } \\ \text { WHO } & \text { World Health Organization }\end{array}$




\section{Competing Interests}

Authors declare that there is no conflict of interest in this study

\section{Authors' Contributions}

Ikiriza Antony conceived and designed the study; Ikiriza Antony, Andinda Maureen, Mugisa Tony and Kamukama Robert collected, analysed, interpreted the data and drafted the manuscript, Rubaihayo John Arseni R Semana critically revised the manuscript. All authors read and approved the final manuscript for submission.

\section{Acknowledgements}

We thank study participants for providing information. Further, we acknowledge the support of Prof. Arseni R Semana of School of Agriculture and Environmental Science of Mountains of the Moon University for his guidance

\section{References}

[1] World Health Organisation (2017), World Malaria Report, a WHO global malaria program accessed at www.who.int on $9^{\text {th }}$ May 2017. WHO international.

[2] World Health Organisation (2014). World Malaria Report. Geneva: World Health Organization.

[3] National Malaria Control Programme (NMCP). (2014). Uganda Malaria Reduction Strategic Plan 2014-2020. Kampala, Uganda.

[4] Lengeler C. (2014). Insecticide-treated bed nets and curtains for preventing malaria. Cochrane Database Syst Rev. 2014; 2: CD000363.

[5] Guyatt HL, Ochola SA, Snow RW (2002): Too poor to pay: charging for Insecticide treated bed nets in highland Kenya. Trop Med Int health 2002, 7: 846-850.
[6] Ministry of Health (MoH). (2015). Uganda Malaria Indicator Report 2014-15. Kampala: Ministry of Health. Retrieved 621 , 2017, from https://dhsprogram.com/pubs/pdf/mis21/mis21.pdf

[7] Uganda Bureau of Statistcs (UBOS) and ICF. 2017. Uganda Demographic and Health Survey 2016: Key Indicators Report. Kampala, Uganda: UBOS, and Rockville, Maryland, USA: UBOS and ICF.

[8] Kish, Leslie (1965): Survey Sampling. New York: John Wiely and Sons, Inc. p. 78-94.

[9] Binka et al, (2009), Impact of spatial distribution of permethrin-impregnated bed nets on child mortality in rural northern Ghana. Am J Trop Med Hyg, 59: 80-85.

[10] Biadgilign, S, Reda, A \& Kedir, H (2012), 'Determinants of ownership and utilisation of insecticide-treated bed nets for malaria control in Eastern Ethiopia', Journal of Tropical medicine.

[11] Gobena, T, Berhane, Y \& Worka, A, (2012), 'Low longlasting insecticide nets use among household members for protection against mosquito bite in Kerse, Eastern Ethiopia', Research article.

[12] Axame, Wisdom \& Kweku, Margaret \& Amelor, Sedoafia \& Kye-Duodu, Gideon \& Agboli, Eric \& Agbemafle, Isaac \& Kwami Takramah, Wisdom \& Tarkang, Elvis \& Binka, Fred. (2016). Ownership and Utilization of Long Lasting Insecticide Treated Nets (LLIN) and Factors Associated to NonUtilization Among Pregnant Women in Ho Municipality of Ghana. 2. 35-42. 10.11648/j.cajph.20160201.16.

[13] Onwejekwe O, Akpala C, Ghasi S, Shu E, Okonkwo P, (2013). How do rural households perceive and prioritize malaria and mosquito nets? A study in five communities of Nigeria. Public Health 2015, 114: 407-410.

[14] Pulford, J., Hetzel, W. M., Bryant, M.., Siba, M. P. and Mueller, I., (2011). Reported reasons for not using a mosquito net when one is available: a review of the published literature. Malar J. 2011, 10: 83. 